\title{
Obituary
}

\section{Mohammed Ibrahim Khalifa al-Mashai 1 January 1957-2 April 2021}

\author{
David J. Mattingly \\ Roman Archaeology, University of Leicester, Leicester, UK
}

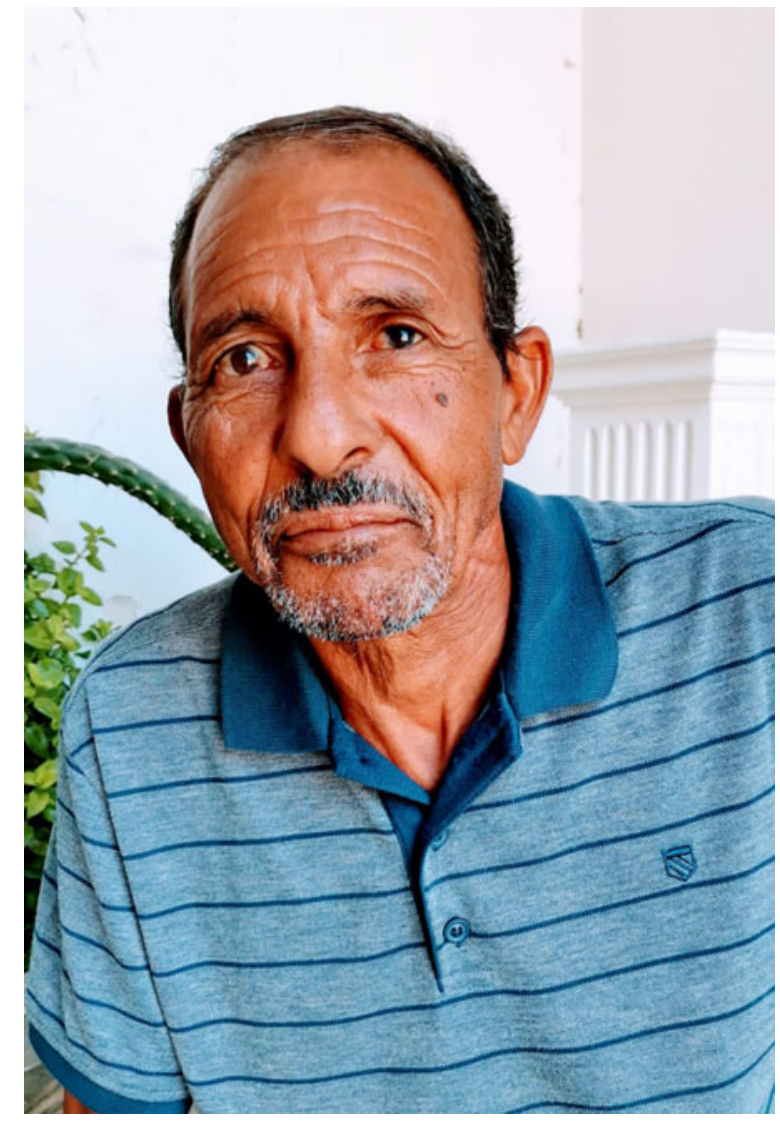

Figure 1. Mohammed al-Mashai in 2019. (Source: Mohammed Fakroun).

Mohammed al-Mashai, who has died at the too young age of 64, was one of the most prominent archaeologists from Libya's southern region of Fazzan. He was born in Qutta in the Wadi ash-Shati in 1957 and received his schooling in Brak, Sabha and Tripoli. He studied archaeology at the University of Benghazi, where he was also a fine athlete. After graduating in 1981, he joined the Department of Antiquities (DoA) and I first met him when he was one of the DoA staff sent that year to participate in the Anglo-Libyan UNESCO Libyan Valleys Survey. He made an immediate impression on me with his charm, his great interest in and enthusiasm for the work and his knowledge of western pop music and culture. In the harsh fieldwork conditions, not many of

Cite this article: Mattingly DJ (2021). Mohammed Ibrahim Khalifa al-Mashai January 1957-2 April 2021. Libyan Studies 52, 11-11. https://doi.org/10.1017/lis.2021.21 the team came close to matching his finely turned out fashion sense either.

For much of the 1980s he was based in the north-west of Libya, where he did important work in the Jabal Nafusa on the Islamic architecture of the region. However, in 1991 he became Controller of the huge desert area of Fazzan in south-west Libya where he was to play a vital role for much of the next decade. This was a really transformative period for the archaeology of Fazzan, which for many years had been something of a backwater. The one notable exception was the Italian mission to the Akakus region, founded by F. Mori, but this too grew in scale in the 1990s, as its leadership passed on to M. Liverani and then S. di Lernia and its remit broadened from recording the prehistoric rock art to investigating more thoroughly the environmental and broader archaeological context of early Saharan peoples. The German researcher $\mathrm{H}$. Ziegert was also active at a number of sites in Fazzan and, in part facilitated by an expansion of oil exploration opening up new paths of access, the rock art of the Wadi ash-Shati and Massak Sataffat started to be explored by a number of academic and amateur researchers (J.-L. Le Quellec, R. and G. Lutz and A. and A.-M. van Albada). Finally, British work on the Garamantes, following on pioneering studies by Charles Daniels between 1958-1977, was resumed in 1997 under my direction. The energy, vision and strong support of Mohammed al-Mashai was crucial in enabling this expansion of work.

He also undertook the re-establishment of a museum at Jarma, bringing back its Garamantian and prehistoric treasures from Sabha and this provided an important focus for visitors when desert tourism started to take off from the late 1990s. He took the initial steps towards establishing a new administrative centre for the DoA at Jarma and restoration and conservation work was undertaken on numerous monuments during this period, including at the mudbrick towns of Jarma and Ghat. He was also involved in brokering many of the agreements with oil companies that saw them undertake a higher level of survey and recording in mitigation for the inevitable damage caused by prospection activity.

I have many warm memories of working closely with him on the Fazzan Project in the late 1990s. His practical contributions to the work were considerable and we shared a common vision of making the Garamantes more celebrated within Libya and beyond. We also had our share of adventures and misadventures, as when two of our vehicles broke down in the sand sea on the same day, necessitating a difficult rescue of the team as dusk fell...

After a period working back in the north of Libya for the DoA, Mohammed returned to the Controllership of Fazzan from 20092010, though by then he was visibly not in the best of health. Nonetheless, he remained a strong supporter of the work of the foreign missions in this second spell in charge and was always a proud champion of Libya's heritage. 